\section{ABO mismatched platelet transfusions in trauma patients}

In the study by Nascimento and colleagues, ${ }^{1}$ the patients who received increased plasma and platelet transfusions had greater mortality due to bleeding (22\%) than the control group $(9 \%)$, albeit not statistically significantly so. Nonetheless, it raises the question of whether the plasma and platelet transfusion worsened hemorrhage rather than mitigated it. One possible mechanism is the administration of ABO non-identical plasma and platelets. Preliminary published observational data show that trauma patients receiving $\mathrm{ABO}$ non-identical (mismatched) platelets have increased red cell transfusion needs, as do patients who experience serious blood loss during surgery in general. ${ }^{2,3} \mathrm{~A}$ possible mechanism is that exposure of platelets and endothelial cells to incompatible anti-A and anti-B antibody impairs platelet function, coagulation and hemostasis. ${ }^{4}$ That group $\mathrm{O}$ individuals have much lower levels of von Willebrand factor than non-O individuals is also well established.

Have the authors considered analyzing their data according to how much $\mathrm{ABO}$ incompatible/non-identical plasma or platelet transfusions were given, or the $\mathrm{ABO}$ types of the patients? This variable might have contributed to the increased hemorrhagic mortality seen in the recipients of larger amounts of ostensibly hemostatic blood components.

\section{Neil Blumberg MD}

Professor, University of Rochester Medical Center, Rochester, NY

\section{References}

1. Nascimento B, Callum J, Tien H, et al. Effect of a fixed-ratio $(1: 1: 1)$ transfusion protocol versus laboratory-results-guided transfusion in patients with severe trauma: a randomized feasibility trial. CMAJ 2013;185:E583-9.

2. Fialkow LB, Zucchiatti A, Cheng J, et al. ABO nonidentical transfusions and red blood cell usage in blunt trauma patients. Transfusion 2007;47(Suppl): 192A-3A.

3. Refaai MA, Fialkow LB, Heal JM, et al. An association of $\mathrm{ABO}$ mismatched platelet and cryoprecipitate transfusions with increased red cell transfusion needs and mortality in surgical patients. Vox Sang 2011;101:55-60

4. Refaai MA, Carter J, Henrichs KF, et al. Alterations of platelet function and clot formation kinetics following in vitro exposure to anti-A and -B antibodies. Transfusion 2013;53:382-93.

CMAJ 2014. DOI:10.1503/cmaj.114-0001

\section{Patient satisfaction}

The CMAJ commentary by Detsky and Shaul ${ }^{1}$ on incentives to improve patient satisfaction is both thought provoking and relevant to day-to-day practice.

Yankelovich $^{2}$ points out that despite better methods of measuring public opinion, little is known about how to improve its quality. Although information has become widely available, it plays only a limited role in shaping public opinion. Opinion polls can be misleading because they do not distinguish between people's immediate reactions and their thoughtful, considered judgments. Patient satisfaction surveys often fail to even measure, let alone correct for, the nature, severity and intractability of the conditions for which care is received. This is a particular problem for teaching hospitals, where the most difficult and complex cases are concentrated.

Undue emphasis on patient satisfaction may make providing services to those most in need impossible for fear of negative repercussions. Added to this is the growing list of for-profit websites that allow anonymous public postings. Many institutions have established patient relations units whose actions are often seen by treating physicians as barriers to following best practices.

At the same time as mandating assessments of patient satisfaction, governments have expressed increasing unwillingness to pay for medically unnecessary measures that would increase satisfaction, such as imaging studies for low-back pain.

\section{Larry M. Picard MD}

Wasser Pain Management Centre, Mount Sinai Hospital, Toronto, Ont.

\section{References}

1. Detsky J, Shaul RZ. Incentives to increase patient satisfaction: Are we doing more harm than good? CMAJ 2013;185:1199-1200.
2. Yankelovich D. Coming to public judgment: making democracy work in a complex world. Syracuse (NY): Syracuse University Press; 1991:258.

CMAJ 2014. DOI:10.1503/cmaj.114-0002

\section{Job strain and lifestyle factors}

The article by Kivimäki and colleagues includes several methodological and interpretational errors.

First, we believe the authors should have excluded obesity from their definition of an unhealthy lifestyle. The authors defined an unhealthy lifestyle arbitrarily as a combination of the following four risk factors of coronary artery disease: smoking, heavy drinking, leisure-time physical inactivity and obesity. Although the first three risk factors may be considered lifestyle risk factors, obesity has a multifactorial etiology and cannot be simplistically labelled a lifestyle risk factor. Therefore, the study's results likely overestimate the effect of an "unhealthy lifestyle" on coronary artery disease.

Second, the authors should have made clear that two of the three behavioural risk factors (heavy drinking and leisure-time physical inactivity) did not offset the impact of job strain on coronary artery disease. Figure 1 in the article by Kivimäki and colleagues ${ }^{1}$ indicates that there would be no significant reduction in the risk of coronary artery disease from reducing heavy drinking behaviour or physical inactivity among workers with job strain. Rather, it indicates the importance of addressing both job strain and unhealthy behavioural risk factors for prevention of coronary artery disease. Emerging evidence shows that organizational- or task-level interventions for increasing job control and decreasing high job demands can be beneficial for the health of workers and organizations. ${ }^{2,3}$

Third, the conclusion of the authors ("a healthy lifestyle may substantially reduce disease risk among people with job strain") is misleading; $84.3 \%$ of workers with job strain had none or only one of the four risk factors, and in 
this group there was no significant effect modification of any one of the four risk factors on the association between job strain and coronary artery disease. Therefore, the conclusion is irrelevant for the majority of the workers with job strain. Job strain, an adverse working condition, may be a structural barrier that keeps workers from adopting and maintaining healthy behaviours as implied in another arti$\mathrm{cle}^{4}$ by the same research group.

Last, throughout the article, the authors equate job strain with perceived work stress or work stressors in general. The authors inappropriately compared the effects of perceived work stress (i.e., how often participants felt stress at work) in the INTERHEART study with job strain in their study. Equating job strain with work stressors in general ignores other important work stressors (i.e., poor workplace social support, job insecurity, long work hours, and effort-reward imbalance) that have been associated with cardiovascular disease. ${ }^{5}$

\section{BongKyoo Choi ScD, Marnie Dobson PhD, Sangbaek Ko MD, Paul \\ Landsbergis $\mathbf{P h D}$ \\ Center for Occupational and \\ Environmental Health (Choi, Dobson, Ko), University of California, Irvine, Calif.; \\ Yonsei University, Wonju College of Medicine (Ko), Wonju, South Korea; Downstate School of Public Health (Landsbergis), State University of New York, New York, NY.}

\section{References}

1. Kivimäki M, Nyberg ST, Fransson EI, et al. Associations of job strain and lifestyle risk factors with risk of coronary artery disease: a meta-analysis of individual participant data. CMAJ 2013;185:763-9.

2. Egan M, Bambra C, Thomas S, et al. The psychosocial and health effects of workplace reorganisation. 1. A systematic review of organisationallevel interventions that aim to increase employee control. J Epidemiol Community Health 2007;61: 945-54.

3. Bambra C, Egan M, Thomas S, et al. The psychosocial and health effects of workplace reorganisation. 2. A systematic review of task restructuring interventions. J Epidemiol Community Health 2007;61:1028-37.

4. Fransson EI, Heikkilä K, Nyberg ST, et al. Job strain as a risk factor for leisure-time physical inactivity: an individual-participant meta-analysis of up to 170,000 men and women The IPD-Work Consortium. Am J Epidemiol 2012;176:1078-89.

5. Choi B, Schnall P, Ko S, et al. Job strain and coronary heart disease [letter]. Lancet 2013;381:448.

CMAJ 2014. DOI:10.1503/cmaj.114-0003

\section{Doctors must be trained to assess credibility}

According to research highlighted in a CMAJ news article, ${ }^{1}$ Canadian schools are not adequately managing conflicts of interest in undergraduate medical education. Persaud, whose research is discussed in the article, rightly suggests that medical students do not yet possess the knowledge and experience needed to detect biased information. But do trained physicians have the skills to do so?

Lo and $\mathrm{Ott}^{2}$ reported that conflicts of interest are ubiquitous in continuing medical education, and that doctors are underprepared for the task of recognizing when conflicts are influencing the content presented. Lo and $\mathrm{Ott}^{2}$ point out that bias, which undermines the scientific validity of our knowledge, results not only from methodologic shortcomings of research but also from conflicts of interest arising in research or education. Yet, current undergraduate and postgraduate medical training emphasize only the methodologic determinants of systematic bias, and critical appraisal — our evidencebased approach to assessing the quality of evidence - is tantamount to assessing the rigour of a study. In other words, was the study well designed?

The credibility of the source of our information is another crucial consideration that is underappreciated and unexplored. ${ }^{3}$ Is the source reliable? Can we trust in the completeness and integrity of the evidence presented, or are important data missing or are facts potentially distorted? Of serious concern is the credibility of much pharmaceutical industryfunded education and research, which are fraught with publication bias and other forms of misrepresentation. ${ }^{4}$

Assessing credibility requires an understanding of the sociocultural, financial and regulatory context of research and education, as well as an approach, just as we have an approach to the critical appraisal of study design. First, we must recognize that poor credibility is as significant - perhaps even more significant - a threat to the validity of our knowledge as poor methodology. So we had better train physicians to assess it.

Jonathan Fuller BMSc, Ross E.G. Upshur MD MSc, Maya Goldenberg PhD MD/PhD student (Fuller), University of Toronto, Toronto, Ont.; Professor, Department of Family and Community Medicine, Sunnybrook Health Sciences Centre (Upshur); Assistant Professor (Goldenberg), Department of Philosophy, University of Guelph; Toronto, Ont.

\section{References}

1. Glauser W. Pharma influence widespread at medical schools: study. CMAJ 2013;185:1121-2.

2. Lo B, Ott C. What is the enemy in CME, conflicts of interest or bias? JAMA 2013;310:1019-20.

3. Upshur R. Making the grade: assuring trustworthiness in evidence. Perspect Biol Med 2009;52:26475

4. Goldacre B. Bad pharma: How drug companies mislead doctors and harm patients. New York (NY): Faber and Faber; 2012.

CMAJ 2014. DOI:10.1503/cmaj.114-0004

\section{- Correction}

\section{Atlantic Canada being served for cancer genotyping}

A news story that appeared in the Oct. 1, 2013, issue of CMAJ incorrectly stated that Atlantic Canada has no facility to test for crucial genetic mutations that could improve some patients' treatment options. In fact, a Halifax-based screening program was launched in September 2012 and has subsequently tested more than 500 cases from throughout the region, and offers this additional level of care to qualifying individuals from all four provinces. CMAJ apologizes for any this error and omission.

\section{Reference}

1. Louheed T. Uneven accessibility to biomarker test for lung cancer. CMAJ 2013;185:1203.

CMAJ 2014. DOI:10.1503/cmaj.114-0005 